\title{
Association of short-term exposure to air pollution with mortality in a middle eastern tourist city
}

\author{
Tayebeh Khosravi ${ }^{1}$ • Mostafa Hadei ${ }^{2,3}$ • Philip K. Hopke ${ }^{4,5} \cdot$ Zahra Namvar $^{1}$ • Abbas Shahsavani ${ }^{6,1}$. \\ Seyed Saeed Hashemi Nazari ${ }^{7}$ - Xavier Querol ${ }^{8}$. Masoumeh Rahmatinia ${ }^{1}$. Mohammad Reza Alipour ${ }^{1}$. \\ Maryam Yarahmadi ${ }^{9} \cdot$ Majid Kermani $^{10}$
}

Received: 7 April 2020 / Accepted: 7 July 2020 / Published online: 17 July 2020

(C) Springer Nature B.V. 2020

\begin{abstract}
This study investigated the association of short-term exposure to $\mathrm{PM}_{10}, \mathrm{PM}_{2.5}, \mathrm{NO}_{2}, \mathrm{O}_{3}$, and CO with daily all-cause, cardiovascular, ischemic heart disease (IHD), cerebrovascular, and respiratory deaths in Mashhad, a tourist megacity in Iran (20142018). A distributed-lag-day, nonlinear model (DLNM) and generalized additive model (GAM) based on the quasi-Poisson distribution were used to explore the exposure-lag-day-response associations. The average ( \pm standard deviation) concentrations of $\mathrm{PM}_{10}, \mathrm{PM}_{2.5}, \mathrm{NO}_{2}, \mathrm{O}_{3}$, and $\mathrm{CO}$ were $67.1( \pm 35.5), 29.6( \pm 14.2), 57.3( \pm 24.1), 55.9( \pm 16.9)$, and $1907.6( \pm 1362.7) \mu \mathrm{g} / \mathrm{m}^{3}$, respectively. $\mathrm{NO}_{2}$ was associated with $\mathrm{IHD}$ mortality in lag-days 0 to $0-7$, and lag-day 1 . The relative risks (RRs) for a $10 \mu \mathrm{g} / \mathrm{m}^{3}$ increase in $\mathrm{NO}_{2}$ ranged from 1.01 (95\% CI 0.93, 1.11) at lag-day 0 to 1.04 (95\% CI 0.94, 1.16) and 1.03 (95\% CI 0.93, 1.14) for lag-day 0-1 (cumulative) and lag-day 1 (non-cumulative), respectively. For all-cause mortality, cumulative exposure to $\mathrm{PM}_{2.5}$ for lag-day 0-7 $(1.07,95 \%$ CI $1.00,1.15)$ and non-cumulative exposure to $\mathrm{NO}_{2}$ at lag-day $6(1.02,95 \% \mathrm{CI} 1.00,1.03)$ were significant. Exposure to $\mathrm{PM}_{10}$ (per $10 \mu \mathrm{g} / \mathrm{m}^{3}$ ) was significantly associated with respiratory mortality at several lag-days. Adjusting for Ramadan did not significantly affect the results. $\mathrm{PM}_{10}$ had significant associations with respiratory mortality of people $>65$ years old, and men for several lag-days. For IHD, $\mathrm{NO}_{2}$ affected older people, and men and women over different lagdays. Results of multi-pollutant models were similar to the single-pollutant model outcomes. In conclusion, $\mathrm{NO}_{2}$ and $\mathrm{PM}_{10}$ had more significant relationships with adverse health outcomes than the other pollutants.
\end{abstract}

Keywords Particulate matter $\cdot$ Particles $\cdot$ Outdoor air pollution $\cdot$ Health $\cdot$ Mashhad

Electronic supplementary material The online version of this article (https://doi.org/10.1007/s11869-020-00875-x) contains supplementary material, which is available to authorized users.

Abbas Shahsavani

ashahsavani@gmail.com

1 Department of Environmental Health Engineering, School of Public Health and Safety, Shahid Beheshti University of Medical Sciences, Tehran, Iran

2 Department of Environmental Health Engineering, School of Public Health, Tehran University of Medical Sciences, Tehran, Iran

3 Students' Scientific Research Center (SSRC), Tehran University of Medical Sciences, Tehran, Iran

4 Center for Air Resources Engineering and Science, Clarkson University, Potsdam, NY, USA
5 Department of Public Health Sciences, University of Rochester School of Medicine and Dentistry, Rochester, NY, USA

6 Environmental and Occupational Hazards Control Research Center, Shahid Beheshti University of Medical Sciences, Tehran, Iran

7 Department of Epidemiology, School of Public Health and Safety, Shahid Beheshti University of Medical Sciences, Tehran, Iran

8 Institute of Environmental Assessment and Water Research (IDAEA), Spanish Council for Scientific Research (CSIC), Barcelona, Spain

9 Center of Environmental and Occupational Health, Ministry of Health and Medical Education, Tehran, Iran

10 Research Center for Environmental Health Technology, Iran University of Medical Sciences, Tehran, Iran 


\section{Introduction}

Outdoor air pollution is known to be an important risk factor for human health. About 4.2 million annual deaths have been attributed to exposure to particulate matter worldwide (WHO 2014). Short- and long-term exposure to particulate matter $\left(\mathrm{PM}_{10}\right.$ and $\left.\mathrm{PM}_{2.5}\right)$ and gaseous pollutants such as nitrogen dioxide $\left(\mathrm{NO}_{2}\right)$, ozone $\left(\mathrm{O}_{3}\right)$, and carbon monoxide $(\mathrm{CO})$ have been associated with various health outcomes such as cardiovascular, cerebrovascular, and respiratory mortality and morbidity (Moolgavkar et al. 2013; Nabizadeh et al. 2019; R. Chen et al. 2014). Short-term high exposures from pollution peaks affect daily mortality on the same day or the next few days through their lag-day effects (Liu et al. 2019).

The associations between acute exposure to air pollution and adverse health outcomes have been increasingly reported during recent years (Nabizadeh et al. 2019). Many studies have been performed in most of the world, but especially in Western Europe, Northern America, and China. A study in 38 Chinese large cities found that $\mathrm{PM}_{10}$ exposure was significantly associated with daily mortality with lag-days of up to 2 days (Yin et al. 2017). In another study in 10 US cities, 7-day and 2day averages of $\mathrm{PM}_{10}$ were associated with respiratory and cardiovascular health outcomes, including pneumonia (relative risk $(\mathrm{RR})=2.7 \%$ on average), chronic obstructive pulmonary disease $(1.7 \%)$, all cardiovascular diseases $(1.0 \%)$, and myocardial infarction $(0.7 \%)$ (Braga et al. 2001). In a systematic review by Atkinson et al. (2014), 110 time-series studies investigating the daily mortality and hospitalization were identified through 2011. The overall results of meta-analysis showed that a $10 \mu \mathrm{g} / \mathrm{m}^{3}$ increase in $\mathrm{PM}_{2.5}$ was associated with an average of $1.04 \%$ increase in the number of deaths (Atkinson et al. 2014). In a more comprehensive study, Liu et al. (2019) considered 652 cities worldwide to investigate the effect of short-term exposure to particles. Cumulative 2-day exposure to $\mathrm{PM}_{10}$ increased all cause, cardiovascular, and respiratory mortality by $44 \%, 0.36 \%$, and $0.47 \%$, respectively. The corresponding percentages for $\mathrm{PM}_{2.5}$ were $0.68 \%, 0.55 \%$, and $0.74 \%$, respectively (Liu et al. 2019). However, the authors found that the risks varied substantially by region, indicating the effects of differing population vulnerability and/or differential toxicity of sources, pollutant mixtures, and pollution monitoring (Atkinson et al. 2014).

Air pollution exposure-response associations have been shown to vary by geographical location and different PM compositions (Mohseni Bandpi et al. 2016) with potentially different shapes for the exposure-response curve, and differing effect modifications (Croft et al. 2019; Hopke et al. 2019; Rich et al. 2019). As these factors change geographically and temporally, new analyses in various urban areas can bring additional insights into our current knowledge and understanding about the association between different air pollutants and different health outcomes. In addition, very limited relevant evidence has been published for Iranian cities where high concentrations of air pollutants are normally monitored relative to many other parts of the world (Hadei et al. 2018; Ghorbani et al. 2017; Ghorbani et al. 2019). One of the typical limitations of assessing the impacts of air pollutions is the lack of locally relevant relative risk (RR) values. This work will provide RR values for a number of important health outcomes and those will help provide more accurate air pollution health assessments in other locations in the region. The present study investigated the association of short-term exposure to $\mathrm{PM}_{10}, \mathrm{PM}_{2.5}, \mathrm{NO}_{2}, \mathrm{O}_{3}$, and $\mathrm{CO}$ with all cause, total cardiovascular, ischemic heart disease (IHD), total cerebrovascular, and total respiratory deaths in Mashhad Iran during 2014-2018.

\section{Methods}

\section{Study area}

Mashhad is located in northeastern Iran $\left(36^{\circ} 18^{\prime} \mathrm{N} 59^{\circ} 36^{\prime} \mathrm{E}\right)$ and has a population about 3 million people. Due to its touristic attractions, millions of people visit this city every year contributing to emission of significant amounts of trafficrelated air pollution. In addition, industrial emissions are another major influence on air quality. In this study, we investigated the associations between short-term exposure to $\mathrm{PM}_{10}$, $\mathrm{PM}_{2.5}, \mathrm{NO}_{2}, \mathrm{O}_{3}$, and $\mathrm{CO}$ and daily cause-specific mortality in Mashhad. The study period was from March 2014 to March 2018.

\section{Exposure assessment}

Hourly concentrations of $\mathrm{PM}_{10}, \mathrm{PM}_{2.5}, \mathrm{NO}_{2}, \mathrm{O}_{3}$, and $\mathrm{CO}$ were acquired from Department of Environment of Iran. Only data from monitoring stations were included that had at least $75 \%$ of hourly concentrations available. In cases where only one station remained, a criterion of at least $50 \%$ were chosen for better estimation of population exposure. The final number of monitors after validation was as follows: $\mathrm{PM}_{10} 11, \mathrm{PM}_{2.5} 12, \mathrm{NO}_{2}$ $11, \mathrm{O}_{3} 1$, and $\mathrm{CO}$ 13. Except for $\mathrm{O}_{3}, 24$-h averages were calculated for other pollutants. For $\mathrm{O}_{3}$, maximum 8-h moving averages were calculated for each day. In addition, daily mean values of air temperature and relative humidity were calculated from data acquired from Meteorological Organization of Iran.

\section{Health outcomes}

The health outcomes considered in this study included: all non-accidental causes of mortality (ICD-10 A00-R99), respiratory diseases (ICD-10 J00-J99), cerebrovascular diseases (ICD-10 I60-I69), ischemic heart disease (IHD, ICD-10 I20I25), and cardiovascular diseases (ICD-10 I00-I99). The daily 
number of deaths for each outcome was obtained from the Ministry of Health and Medical Education of Iran. For all outcomes, the mortality data were categorized in three age groups $<16$ years old, $16-65$ years old, and $>65$ years old.

\section{Statistical analysis}

Due to the non-linear nature of relationship between outdoor air pollution and health, we used a distributed-lag, nonlinear model (DLNM), and a generalized additive model (GAM) based on the quasi-Poisson distribution to explore the exposure-lag-response associations (Guo et al. 2017). We used a single-pollutant model with adjustments for meteorological and time variables.

First, separate cross-basis functions were created for each pollutant and temperature. Then, a basic model was constructed using the defined cross-basis functions, day of week (DOW) as an indicator variable, a dummy variable to control for holidays, a natural spline function of "time" to control for long-term trends $(n=1,2,3, \ldots, 1462)$, and a natural spline function for relative humidity. The following general equation was the result:

$$
\begin{aligned}
& \log \left(E\left(\mu_{t}\right)\right) \alpha+\beta^{*} \text { pollutant }+\gamma^{*} \text { Temperature } \\
& +\mathrm{ns}\left(\text { Time, } \mathrm{df}_{1}\right)+\mathrm{ns}\left(\text { Relative humidity, } \mathrm{df}_{2}\right) \\
& +\delta^{*} \text { DOW }+\varepsilon^{*} \text { Holiday }
\end{aligned}
$$

Where $\left(\mu_{\mathrm{t}}\right)$ is the expected number of deaths in day $t$. Pollutant and temperature are the cross-basis functions defined in the previous step. $\beta$ and $\gamma$ are the regression coefficients and are the concentration-mortality rates associated with a unit increase in the levels of air pollutant and temperature, respectively. $\mathrm{df}_{1}$ and $\mathrm{df}_{2}$ are the degrees of freedom for time and relative humidity natural spline functions. $\delta$ and $\varepsilon$ are the regression coefficients for the day of week (DOW) and holiday variables.

In the next step, the degrees of freedom for the concentrations/values and lag-days of the air pollutant and temperature in cross-basis functions and the degree of freedom for relative humidity variable in basic model were determined. To this, a trial and error approach was used to select the mentioned degrees of freedom from a range of 1 to 7 based on the minimum quasi-Akaike's information criterion (Q-AIC). In this trial and error, to determine the df values, $\mathrm{PM}_{10}$ and allcause mortality were entered into the model. A range of 1-7 was assigned for each $\mathrm{df}$. The model was run for every possibility of df values, and finally, the minimum Q-AIC was found to be 9602 . The assigned dfs for concentrations and lag-days of $\mathrm{PM}_{10}$ were 4 and 3 , for values and lag-days of temperature were 5 and 5 , and for relative humidity was 3 . These degrees of freedom were used in all other models.
In the final stage, to explore the lag-day-effect, up to a 7day lag-day was selected for both cumulative and noncumulative exposures. In this context, non-cumulative refers to the examining the effect of exposure on day 0 to lag-day $n$. Cumulative refers to examining the effect of average concentration during 0 -n days for lag-day 0 -n. Only one pollutant was entered to the model at the time (single-pollutant), and the association was adjusted for temperature, relative humidity, long-term trends, holiday, and day of week.

Given that the mortality rate can change during the Ramadan (Abazid et al. 2018; Zimhony et al. 2018), another model was developed to adjust for the effect of this month. In this model that was similar to the main model, only a binary ( 0 and 1$)$ variable of not-Ramadan or Ramadan were introduced to control for the possible effect of any changes in mortality rate. Sub-group analyses were also conducted for different age groups. The relative risks (RRs) were estimated for a $10 \mu \mathrm{g} / \mathrm{m}^{3}$ increase in $\mathrm{PM}_{10}, \mathrm{PM}_{2.5}$, and $\mathrm{NO}_{2}$, a $1000 \mu \mathrm{g} / \mathrm{m}^{3}$ increase in $\mathrm{CO}$, and also a $10 \mu \mathrm{g} / \mathrm{m}^{3}$ increase in $\mathrm{O}_{3}$ with a threshold of $70 \mu \mathrm{g} / \mathrm{m}^{3}$. In addition, a multipollutant model was developed with the simultaneous presence of $\mathrm{PM}_{2.5}$ and $\mathrm{NO}_{2}$ to explore their effect on all-cause and IHD mortality.

All analyses were performed using $\mathrm{R}$ software (version 3.3.3) and the $d l n m$ package. The RRs were reported at the 95\% confidence level.

\section{Results}

The relationships between exposure to five criteria air pollutants $\left(\mathrm{PM}_{10}, \mathrm{PM}_{2.5}, \mathrm{NO}_{2}, \mathrm{O}_{3}\right.$, and $\left.\mathrm{CO}\right)$ and all-non-accidental cause and cause-specific mortality with lag-days up to 7 days were investigated. The descriptive statistics for the air pollutants concentrations, daily number of deaths, and daily meteorological parameter values are presented in Table 1. During the study period, 57,235 deaths due to all non-accidental causes have been recorded, of which $33.4 \%(n=19,134)$ and $9.2 \%(n=5290)$ were from cardiovascular and respiratory diseases, respectively. The average ( \pm standard deviation) concentrations of $\mathrm{PM}_{10}, \mathrm{PM}_{2.5}, \mathrm{NO}_{2}, \mathrm{O}_{3}$, and $\mathrm{CO}$ were 67.1 ( \pm 35.5), $29.6( \pm 14.2), 57.3( \pm 24.1), 55.9( \pm 16.9)$, and 1907.6 $( \pm 1362.7) \mu \mathrm{g} / \mathrm{m}^{3}$, respectively.

Figures 1 and 2 illustrate the results for the associations between cumulative and non-cumulative exposure to particulate matter and gaseous pollutants and IHD mortality. In Fig. 1, same-day exposure to $10 \mu \mathrm{g} / \mathrm{m}^{3}$ increases in $\mathrm{PM}_{10}$ and $\mathrm{PM}_{2.5}$ concentrations showed inconsistent and imprecise associations with daily IHD death with the RRs of 1.01 (95\% CI $0.98,1.03)$ and 1.03 (95\% CI 0.96, 1.10), respectively. In fact, none of the RRs for the IHD-PM relationship was statistically significant. On lag-day 7 , the RRs for $\mathrm{PM}_{10}$ and $\mathrm{PM}_{2.5}$ were $1.01(95 \%$ CI $0.99,1.03)$ and 1.03 (95\% CI 0.97, 1.10), 
Table 1 Descriptive statistics of mortality, air pollution, and meteorological variables

\begin{tabular}{|c|c|c|c|c|c|c|c|c|c|}
\hline Variable & Unit & Sum & Mean daily & SD & Minimum & Q1 & Median & Q3 & Maximum \\
\hline \multicolumn{10}{|l|}{ Mortality } \\
\hline All cause & $\mathrm{N}$ & 57,234 & 39.2 & 8.7 & 13.0 & 33.0 & 38.0 & 45.0 & 95.0 \\
\hline Respiratory & $\mathrm{N}$ & 5290 & 3.6 & 2.4 & 0.0 & 2.0 & 3.0 & 5.0 & 15.0 \\
\hline Cardiovascular & $\mathrm{N}$ & 19,134 & 13.1 & 4.4 & 2.0 & 10.0 & 13.0 & 16.0 & 32.0 \\
\hline Cerebrovascular & $\mathrm{N}$ & 3988 & 2.7 & 1.8 & 0.0 & 1.0 & 2.0 & 4.0 & 10.0 \\
\hline IHD & $\mathrm{N}$ & 5998 & 4.1 & 2.3 & 0.0 & 2.0 & 4.0 & 5.0 & 17.0 \\
\hline \multicolumn{10}{|l|}{ Air pollution } \\
\hline $\mathrm{PM}_{10}$ & $\mu \mathrm{g} / \mathrm{m}^{3}$ & - & 67.1 & 35.5 & 7.1 & 43.7 & 59.3 & 82.6 & 418.4 \\
\hline $\mathrm{PM}_{2.5}$ & $\mu \mathrm{g} / \mathrm{m}^{3}$ & - & 29.6 & 14.2 & 4.9 & 19.6 & 27.0 & 36.1 & 115.1 \\
\hline $\mathrm{NO}_{2}$ & $\mu \mathrm{g} / \mathrm{m}^{3}$ & - & 57.3 & 24.1 & 14.5 & 38.2 & 50.5 & 74.1 & 141.5 \\
\hline $\mathrm{O}_{3}$ & $\mu \mathrm{g} / \mathrm{m}^{3}$ & - & 55.9 & 16.9 & 7.2 & 43.7 & 56.5 & 68.2 & 105.8 \\
\hline $\mathrm{CO}$ & $\mu \mathrm{g} / \mathrm{m}^{3}$ & - & 1908 & 1363 & 713 & 1426 & 1685 & 1977 & 5355 \\
\hline \multicolumn{10}{|l|}{ Meteorological } \\
\hline Temperature & ${ }^{\circ} \mathrm{C}$ & - & 16.4 & 9.8 & -7.0 & 7.7 & 16.8 & 25.4 & 34.7 \\
\hline Relative humidity & $\%$ & & 55.2 & 12.6 & 15.0 & 31.1 & 55.9 & 70.4 & 86.8 \\
\hline
\end{tabular}

respectively, higher than the values for the previous days. For both $\mathrm{PM}_{10}$ and $\mathrm{PM}_{2.5}$, the trend for non-cumulative exposure was decreasing from lag-day 1 to lag-day 3 , and then increased up to lag-day 7 .

For $\mathrm{NO}_{2}$, cumulative exposure at all lag-days and noncumulative exposure at lag-day 1 were significantly associated with the daily mortality of IHD (Fig. 2a, b). The response to the cumulative exposure to $10 \mu \mathrm{g} / \mathrm{m}^{3} \mathrm{NO}_{2}$ increased from $1.12(95 \%$ CI $1.03,1.23)$ for the same day to $1.34(95 \% \mathrm{CI}$ $1.07,1.68$ ) for lag-day 0-7. An inverse trend was observed in case of non-cumulative exposure to $\mathrm{NO}_{2}$, starting from 1.08 $(95 \%$ CI $1.03,1.13)$ for the lag-day 1 and decreasing to 1.01 (95\% CI 0.94, 1.09) for the lag-day 7 . However, all estimates were positive.

No statistically significant associations were found between $10 \mu \mathrm{g} / \mathrm{m}^{3}$ increase in ozone and IHD mortality (Fig. 2c, d). The association increased from $1.01(95 \% \mathrm{CI}$ $0.93,1.11)$ on lag-day 0 to 1.04 (95\% CI $0.94,1.16)$ and 1.03 (95\% CI $0.93,1.14$ ) for the lag-day 0-1 (cumulative) and lag-day 1 (non-cumulative), respectively. An inconsistency was observed in the trends, particularly in the case of lagday 2 and lag-day $0-2$. The overall trend of the lag-dayresponse relationship decreased.

For carbon monoxide (CO), the relationships with daily IHD mortality were not significant for both cumulative and non-cumulative exposures (Fig. 2e, f). Per $1000 \mu \mathrm{g} / \mathrm{m}^{3}$ increase in $\mathrm{CO}$ concentrations, $\mathrm{RRs}$ in the lag-day 0 , lag-day 1, and lag-day 0-1 were 0.99 (95\% CI 0.92, 1.06), 0.99 (95\% CI $0.95,1.03)$, and 0.98 (95\% CI 0.88, 1.09), respectively. On lag-day 4 to lag-day 7 , increases in $\mathrm{CO}$ concentrations were associated with IHD mortality, but the RRs were not statistically significant.
Tables 2 and 3 present the results for the association between non-cumulative and cumulative exposures to $10 \mu \mathrm{g} / \mathrm{m}^{3}$ $\mathrm{PM}_{10}, \mathrm{PM}_{2.5}, \mathrm{NO}_{2}, \mathrm{O}_{3}$, and $1000 \mu \mathrm{g} / \mathrm{m}^{3} \mathrm{CO}$ and causespecific mortality including death due to all causes, respiratory diseases, cardiovascular diseases, and cerebrovascular diseases. All the associations between cumulative and noncumulative exposure to each of the pollutants and health outcomes were positive, but only a few were statistically significant. For all-cause mortality, cumulative exposure to $\mathrm{PM}_{2.5}$ on lag-day 0-7 $(1.07,95 \%$ CI 1.00, 1.15) and non-cumulative exposure to $\mathrm{NO}_{2}$ on lag-day $6(1.02,95 \%$ CI $1.00,1.03)$ were significant.

Exposure to $\mathrm{PM}_{10}$ (per $10 \mu \mathrm{g} / \mathrm{m}^{3}$ increase) was significantly associated to respiratory mortality on lag-day 1 , lag-day 5 , lag-day 6, lag-day 7 (non-cumulative), and lag-days 0-2 to 07 (cumulative). The RRs increased from 1.01 (95\% CI 1.00, $1.03)$ in lag-day 1 to $1.02(95 \%$ CI $1.00,1.04)$ in lag-day 7 , and from $1.04(95 \%$ CI $1.00,1.09)$ in lag-day 0-2 to 1.12 $(95 \%$ CI $1.05,1.20)$ in lag-day $0-7$. Other pollutants did not show any significant associations with daily respiratory mortality.

A $10 \mu \mathrm{g} / \mathrm{m}^{3}$ increase in ozone concentrations was significantly associated with daily deaths from cardiovascular diseases on lag-day $3\left(1.08,95 \%\right.$ CI 1.02, 1.15). $\mathrm{PM}_{10}$ in lag-day 4 , ozone in lag-day 3 , and $\mathrm{CO}$ in lag-day 2 had significant relationships with cerebrovascular mortality with RRs of 1.01 (95\% CI 1.00, 1.03), 1.17 (95\% CI 1.05, 1.31), and 1.05 (95\% CI 1.00, 1.10), respectively. Effects of other pollutants on cardiovascular and cerebrovascular mortality were insignificant.

After adjusting for Ramadan, all the associations were still positive, and the values were very close to those in the base 
PM10 - Cumulative
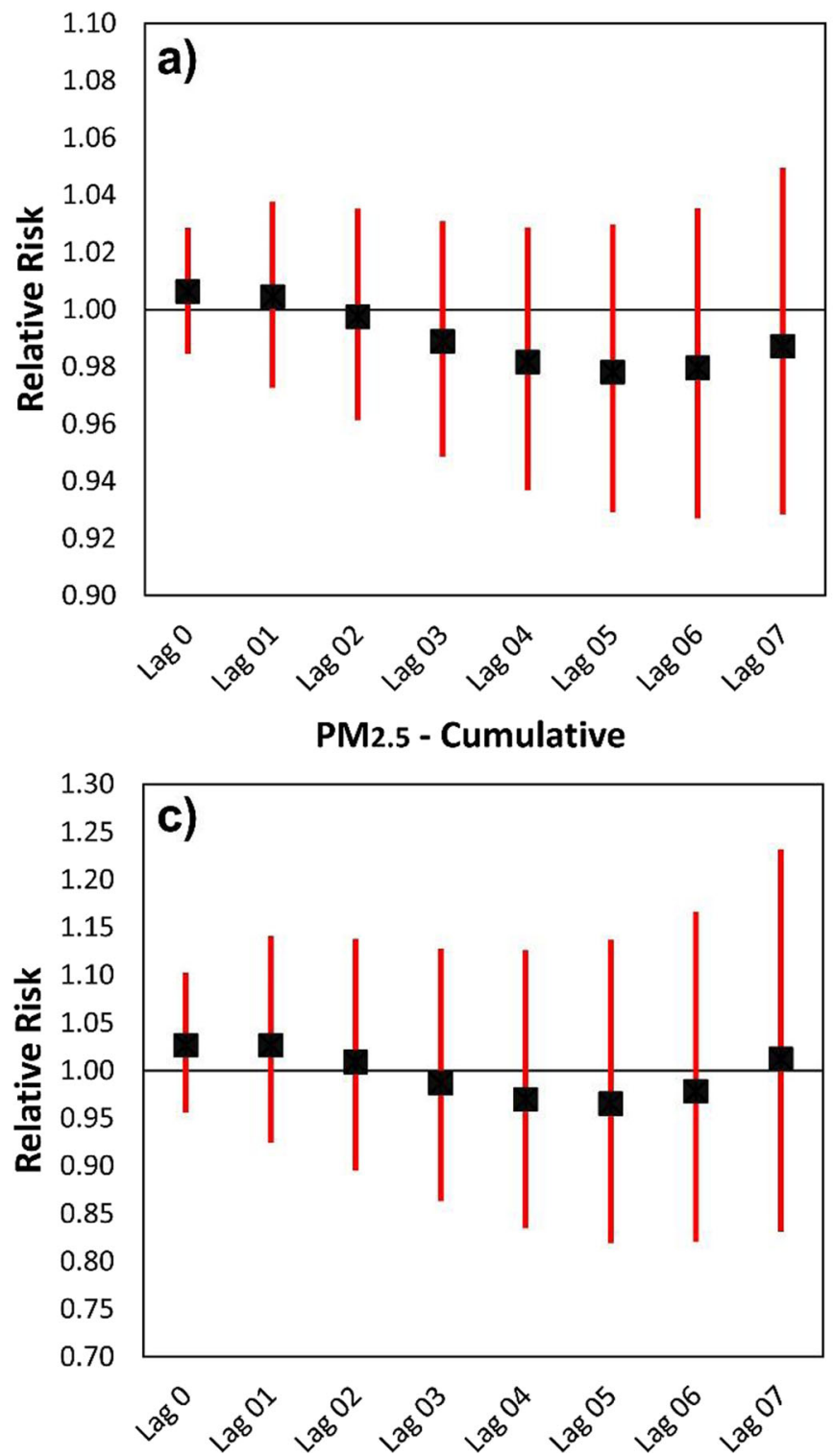

PM10 - Non-cumulative
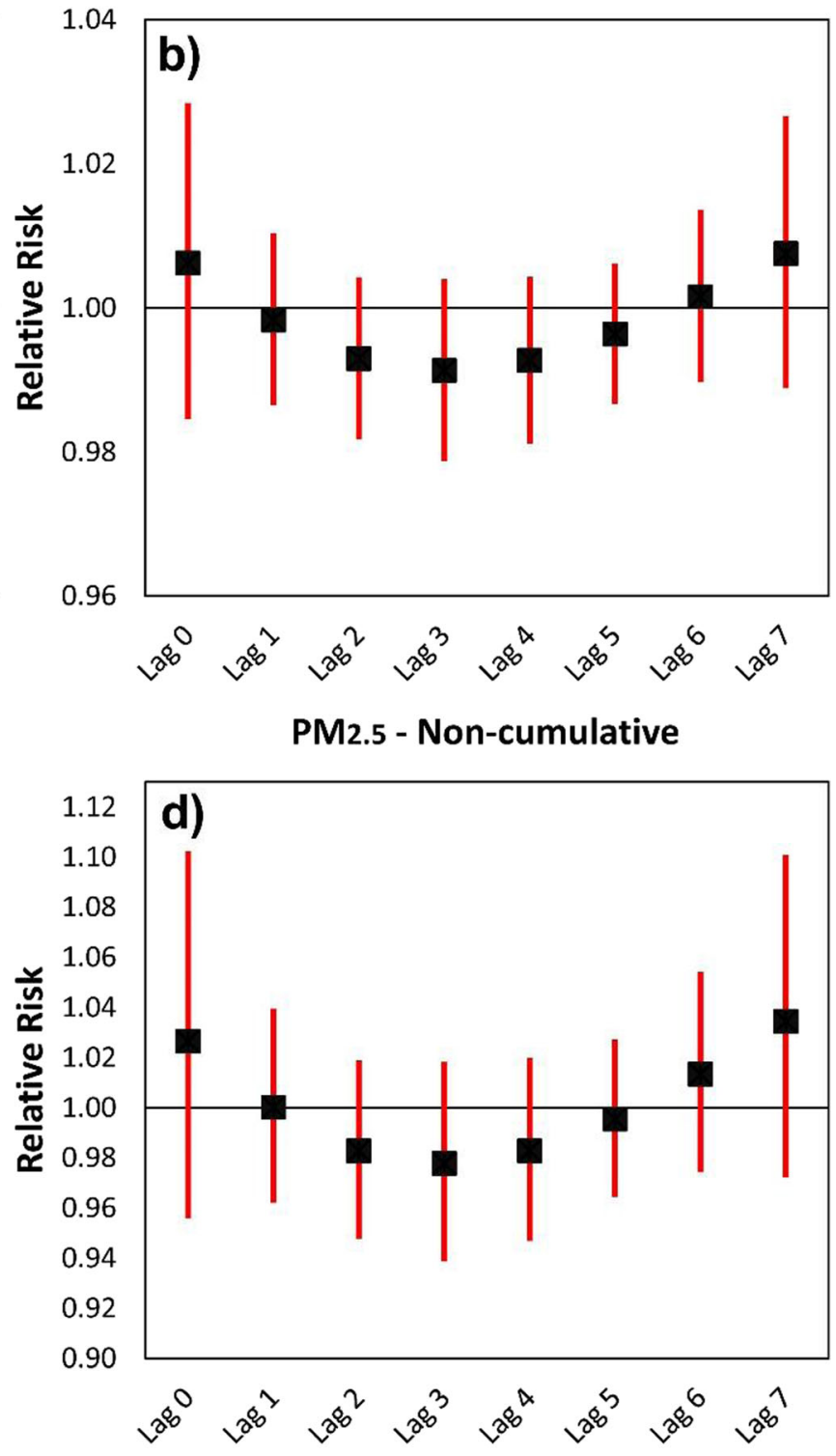

Fig. 1 Relative risks (RRs) for the association of cumulative and non-cumulative exposure to $\mathbf{a}$ and $\mathbf{b} \mathrm{PM}_{10}$. $\mathbf{c}$ and $\mathbf{d} \mathrm{PM}_{2.5}$ with IHD mortality

model (unadjusted for Ramadan), but a few changes in the RR values were observed (Tables A1 and A2 in the Appendix). For instance, the association between non-cumulative exposure to $\mathrm{NO}_{2}$ and all-cause mortality in lag-day 6, noncumulative exposure to $\mathrm{CO}$ and cerebrovascular mortality in lag-day 3 and cumulative exposure to $\mathrm{PM}_{2.5}$ and all-cause mortality in lag-day 0-7 were statistically insignificant in the Ramadan-adjusted model. In addition, cumulative exposure to $\mathrm{PM}_{10}$ and respiratory mortality in lag-day $0-1$ was significant in this model. No other remarkable changes in the RR values and patterns can be identified.

Sub-group analyses were conducted to investigate the effect modification of age and gender. Age was stratified into three groups: $<16,16-65$, and $>65$ years old. The results of subgroup analysis are presented in Tables A3 to A12 in the
Appendix. All the RRs were positive, but only a few were statistically significant. Table 4 presents the $\mathrm{PM}_{10}$ respiratory mortality and $\mathrm{NO}_{2}$ IHD mortality relationships. The daily death rate due to respiratory causes for people aged over 65 years was significantly associated with the exposure to $\mathrm{PM}_{10}$ on previous days, i.e., lag-day 0-1 (1.04, 95\% CI $1.00,1.09)$ to lag-day $0-7(1.14,95 \%$ CI $1.06,1.24)$. The relationships on lag-day 1 , lag-day 5 , and lag-day 6 were significant. In addition, exposure to $\mathrm{PM}_{10}$ showed a stronger association for women than men. The cumulative exposure associations were statistically significant from lag-day 0-1 $(1.09,95 \%$ CI $1.04,1.15)$ to lag-day $0-7(1.20,95 \% \mathrm{CI}$ $1.09,1.32)$. The same-day exposure to $\mathrm{PM}_{10}$ was also associated with a $5.9 \%$ RR for respiratory mortality in women (1.06, 95\% CI 1.02, 1.10). 

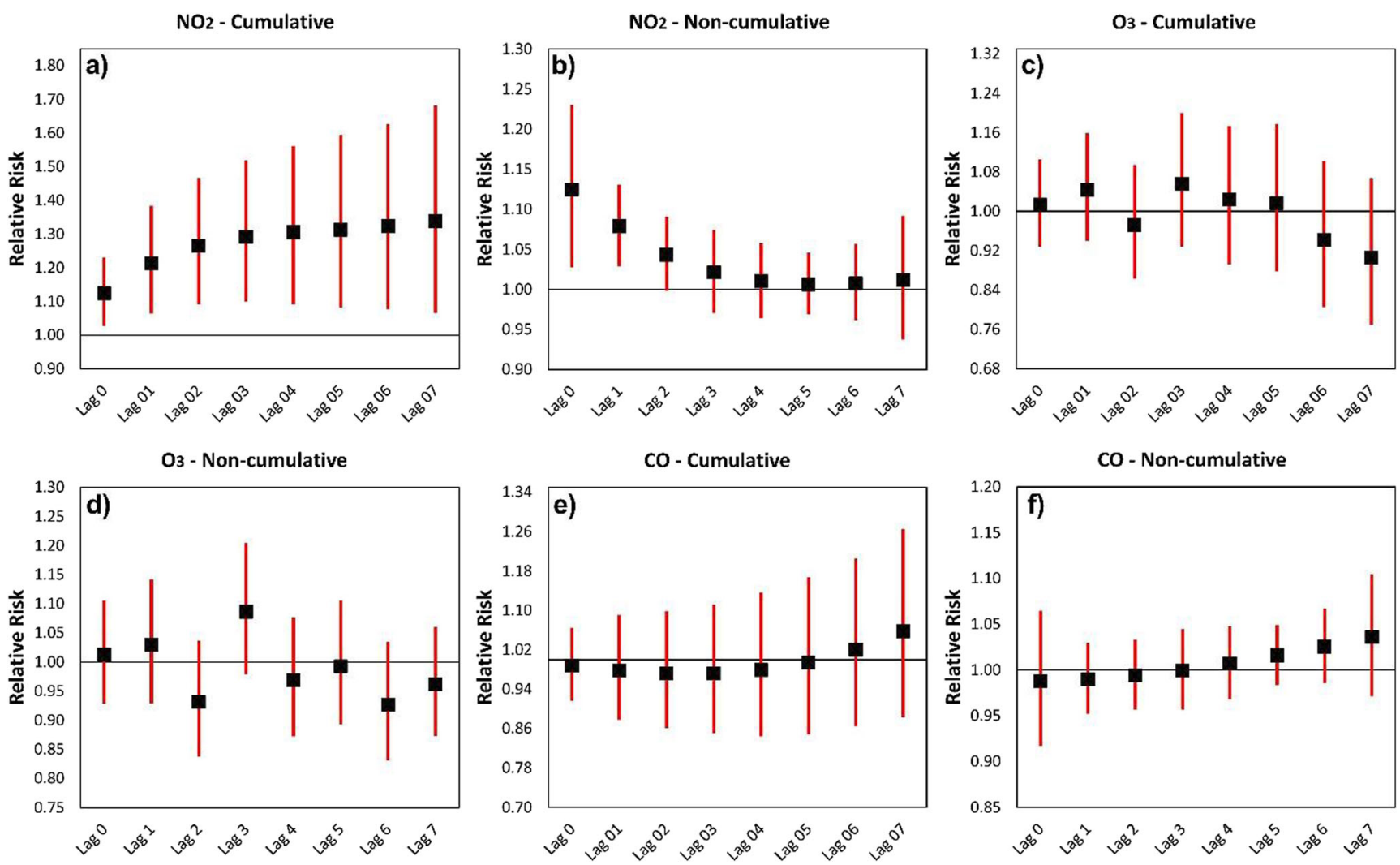

Fig. 2 Relative risks (RRs) for the association of cumulative and non-cumulative exposure to a and $\mathbf{b} \mathrm{NO}_{2}\left(10 \mu \mathrm{g} / \mathrm{m}^{3}\right)$. $\mathbf{c}$ and $\mathbf{d ~ O} \mathrm{O}_{3}\left(10 \mu \mathrm{g} / \mathrm{m}^{3}\right)$. e and $\mathbf{f}$ $\mathrm{CO}\left(1000 \mu \mathrm{g} / \mathrm{m}^{3}\right)$ with IHD mortality

A $10 \mu \mathrm{g} / \mathrm{m}^{3}$ increase in concentrations of $\mathrm{NO}_{2}$ had significant associations with IHD mortality. The RRs of $1.16(95 \%$ CI 1.04, 1.29), 1.10 (95\% CI 1.04, 1.16), and 1.06 (95\% CI $1.01,1.12$ ) were estimated for the lag-day 0 , lag-day 1 , and lag-day 2. Cumulative exposure to $\mathrm{NO}_{2}$ was associated with IHD mortality on all lag-days, namely, from lag-day $0-1$ $(1.27,05 \%$ CI $1.09,1.49)$ to lag-day $0-7(1.49,95 \%$ CI $1.14,1.94)$. The associations for younger age groups were insignificant. IHD mortalities in both men and women were affected by $\mathrm{NO}_{2}$. The current-day exposure caused $13.4 \%$ increase in IHD mortality in men. Cumulative exposure in lag-day $0-1$ was also associated with IHD death in men with an RR $(1.22,95 \%$ CI $1.03,1.44)$ slightly higher than that for women $(1.21,95 \%$ CI 1.01, 1.46).

For controlling the effect of co-exposures, a multi-pollutant model was developed including $\mathrm{PM}_{2.5}$ and $\mathrm{NO}_{2}$ (Table 5). The results of multi-pollutant model were mostly similar to the single-pollutant model. All the RRs for $\mathrm{PM}_{2.5}$ with allcause and IHD mortality were positive, but not significant. In addition, similar to the single-pollutant model, the association of $\mathrm{NO}_{2}$ with IHD mortality was significant on all cumulative lag-days and also on lag-days 0 and 1 , with RRs slightly higher in most cases. The RR for $\mathrm{NO}_{2} \mathrm{IHD}$ on lag-day 0 in the single-pollutant model was 1.13 (95\% CI 1.03, 1.23), while in the multi-pollutant model, it was 1.13 (95\% CI 1.03, 1.24). For all-cause death, despite the single-pollutant model (1.08,
$95 \%$ CI 1.00, 1.17), the association of cumulative exposure in lag-day 0-7 was significant $(1.08,95 \%$ CI 1.00, 1.17).

\section{Discussion}

This study is one of the few to evaluate the short-term associations of exposure to air pollution and health in Iran. In this study, exposure to $\mathrm{PM}_{10}, \mathrm{PM}_{2.5}, \mathrm{NO}_{2}, \mathrm{O}_{3}$, and $\mathrm{CO}$ and causespecific mortality were investigated. The results showed that $\mathrm{NO}_{2}$ had a stronger association with IHD deaths compared with the other pollutants. In addition, mortality due to respiratory causes for the entire population, older people, and women was more significantly associated with $\mathrm{PM}_{10}$. People aged over 65 years were more susceptible to IHD death due to $\mathrm{PM}_{10}$. Results of the multi-pollutant model were mostly similar to the single-pollutant model.

These results can be compared with the associations found in North America and Western Europe that are used by WHO as the basis for health impact assessment studies around the world (WHO 2013). In the case of $\mathrm{NO}_{2}$, the association with daily all causes of mortality is reported to be 1.0027 (95\% CI $1.0016,1.0038$ ) (WHO 2013), which is lower than our estimates on most lag-days for both cumulative and noncumulative exposures. However, in our study, only noncumulative exposure to $\mathrm{NO}_{2}$ on lag-day $6(1.02,95 \% \mathrm{CI}$ 
Table 2 Relative risks (RRs) for the association of non-cumulative exposure to $10 \mu \mathrm{g} / \mathrm{m}^{3}$ increase in $\mathrm{PM}_{10}, \mathrm{PM}_{2.5}, \mathrm{NO}_{2}, \mathrm{O}_{3}$, and $1000 \mu \mathrm{g} / \mathrm{m}^{3} \mathrm{CO}$

\begin{tabular}{|c|c|c|c|c|}
\hline & All causes & Respiratory & Cardiovascular & Cerebrovascular \\
\hline \multicolumn{5}{|c|}{$\mathrm{PM}_{10}\left(10 \mu \mathrm{g} / \mathrm{m}^{3}\right)$} \\
\hline Lag-day 0 & $1.00(0.99-1.01)$ & $1.02(0.99,1.05)$ & $0.99(0.98,1.00)$ & $0.97(0.95,0.99)$ \\
\hline Lag-day 1 & $1.00(0.99-1.00)$ & $1.01(1.00,1.03)$ & $0.99(0.99,1.00)$ & $0.99(0.98,1.00)$ \\
\hline Lag-day 2 & $1.00(0.99-1.00)$ & $1.01(0.99,1.02)$ & $1.00(0.99,1.00)$ & $1.01(0.99,1.02)$ \\
\hline Lag-day 3 & $1.00(0.99-1.00)$ & $1.01(0.99,1.02)$ & $1.00(0.99,1.01)$ & $1.01(0.99,1.03)$ \\
\hline Lag-day 4 & $1.00(0.99-1.00)$ & $1.01(0.99,1.02)$ & $1.00(0.99,1.01)$ & $1.01(1.00,1.03)$ \\
\hline Lag-day 5 & $1.00(0.99-1.00)$ & $1.01(1.00,1.02)$ & $1.00(0.99,1.00)$ & $1.01(0.99,1.02)$ \\
\hline Lag-day 6 & $1.00(0.99-1.00)$ & $1.02(1.00,1.03)$ & $1.00(0.99,1.00)$ & $1.00(0.98,1.01)$ \\
\hline Lag-day 7 & $1.00(0.99-1.01)$ & $1.02(1.00,1.04)$ & $1.00(0.99,1.01)$ & $0.99(0.96,1.01)$ \\
\hline \multicolumn{5}{|c|}{$\mathrm{PM}_{2.5}\left(10 \mu \mathrm{g} / \mathrm{m}^{3}\right)$} \\
\hline Lag-day 0 & $1.01(0.98,1.03)$ & $0.99(0.92,1.07)$ & $1.00(0.96,1.04)$ & $0.96(0.88,1.04)$ \\
\hline Lag-day 1 & $1.01(0.99,1.02)$ & $1.01(0.97,1.06)$ & $1.00(0.98,1.02)$ & $0.99(0.95,1.03)$ \\
\hline Lag-day 2 & $1.01(0.99,1.02)$ & $1.03(0.99,1.07)$ & $1.00(0.98,1.02)$ & $1.01(0.97,1.05)$ \\
\hline Lag-day 3 & $1.01(0.99,1.02)$ & $1.03(0.99,1.08)$ & $1.00(0.98,1.03)$ & $1.02(0.97,1.07)$ \\
\hline Lag-day 4 & $1.01(0.99,1.02)$ & $1.04(0.99,1.08)$ & $1.00(0.98,1.03)$ & $1.02(0.97,1.06)$ \\
\hline Lag-day 5 & $1.01(0.99,1.02)$ & $1.03(0.99,1.07)$ & $1.01(0.99,1.03)$ & $1.00(0.97,1.04)$ \\
\hline Lag-day 6 & $1.01(0.99,1.02)$ & $1.02(0.98,1.07)$ & $1.01(0.99,1.03)$ & $0.98(0.94,1.03)$ \\
\hline Lag-day 7 & $1.01(0.99,1.03)$ & $1.01(0.95,1.08)$ & $1.01(0.98,1.05)$ & $0.96(0.90,1.03)$ \\
\hline \multicolumn{5}{|c|}{$\mathrm{NO}_{2}\left(10 \mu \mathrm{g} / \mathrm{m}^{3}\right)$} \\
\hline Lag-day 0 & $1.00(0.97,1.04)$ & $1.01(0.92,1.12)$ & $1.01(0.96,1.06)$ & $0.92(0.83,1.01)$ \\
\hline Lag-day 1 & $1.00(0.99,1.02)$ & $1.01(0.96,1.06)$ & $1.01(0.99,1.04)$ & $0.97(0.92,1.03)$ \\
\hline Lag-day 2 & $1.00(0.99,1.02)$ & $1.01(0.96,1.06)$ & $1.02(0.99,1.04)$ & $1.02(0.97,1.07)$ \\
\hline Lag-day 3 & $1.00(0.99,1.02)$ & $1.00(0.95,1.06)$ & $1.02(0.99,1.05)$ & $1.04(0.99,1.11)$ \\
\hline Lag-day 4 & $1.01(0.99,1.02)$ & $0.99(0.95,1.05)$ & $1.02(0.99,1.04)$ & $1.05(0.99,1.11)$ \\
\hline Lag-day 5 & $1.01(0.99,1.03)$ & $0.99(0.96,1.04)$ & $1.01(0.99,1.04)$ & $1.04(0.99,1.09)$ \\
\hline Lag-day 6 & $1.02(1.00,1.03)$ & $0.99(0.94,1.05)$ & $1.01(0.99,1.04)$ & $1.02(0.97,1.08)$ \\
\hline Lag-day 7 & $1.02(0.99,1.05)$ & $0.99(0.91,1.08)$ & $1.01(0.97,1.05)$ & $0.99(0.92,1.09)$ \\
\hline \multicolumn{5}{|c|}{$\mathrm{O}_{3}\left(10 \mu \mathrm{g} / \mathrm{m}^{3}\right)$} \\
\hline Lag-day 0 & $0.99(0.96,1.02)$ & $0.98(0.89,1.08)$ & $0.98(0.94,1.03)$ & $0.98(0.89,1.08)$ \\
\hline Lag-day 1 & $1.02(0.98,1.05)$ & $1.00(0.89,1.12)$ & $1.04(0.98,1.10)$ & $0.99(0.88,1.11)$ \\
\hline Lag-day 2 & $1.00(0.96,1.03)$ & $1.04(0.93,1.16)$ & $0.95(0.90,1.00)$ & $0.96(0.85,1.08)$ \\
\hline Lag-day 3 & $1.02(0.98,1.05)$ & $0.96(0.85,1.08)$ & $1.08(1.02,1.15)$ & $1.17(1.05,1.31)$ \\
\hline Lag-day 4 & $0.98(0.95,1.02)$ & $0.95(0.85,1.07)$ & $0.98(0.92,1.03)$ & $0.92(0.82,1.03)$ \\
\hline Lag-day 5 & $1.01(0.97,1.04)$ & $1.05(0.94,1.17)$ & $0.99(0.94,1.05)$ & $0.92(0.82,1.03)$ \\
\hline Lag-day 6 & $0.98(0.95,1.02)$ & $1.03(0.91,1.15)$ & $0.96(0.91,1.02)$ & $1.01(0.90,1.13)$ \\
\hline Lag-day 7 & $1.02(0.99,1.06)$ & $1.04(0.94,1.15)$ & $1.01(0.96,1.06)$ & $0.99(0.89,1.10)$ \\
\hline \multicolumn{5}{|c|}{$\mathrm{CO}\left(1000 \mu \mathrm{g} / \mathrm{m}^{3}\right)$} \\
\hline Lag-day 0 & $1.00(0.97,1.02)$ & $0.99(0.91,1.07)$ & $0.98(0.94,1.02)$ & $1.00(0.91,1.09)$ \\
\hline Lag-day 1 & $0.99(0.98,1.01)$ & $0.98(0.94,1.02)$ & $1.00(0.98,1.02)$ & $1.03(0.98,1.08)$ \\
\hline Lag-day 2 & $0.99(0.98,1.01)$ & $0.98(0.94,1.02)$ & $1.01(0.99,1.04)$ & $1.05(1.00,1.10)$ \\
\hline Lag-day 3 & $1.00(0.98,1.01)$ & $0.98(0.94,1.03)$ & $1.02(0.99,1.04)$ & $1.05(0.99,1.10)$ \\
\hline Lag-day 4 & $1.00(0.99,1.01)$ & $1.00(0.96,1.04)$ & $1.02(0.99,1.04)$ & $1.03(0.98,1.08)$ \\
\hline Lag-day 5 & $1.00(0.99,1.01)$ & $1.02(0.98,1.05)$ & $1.01(0.99,1.03)$ & $1.00(0.96,1.04)$ \\
\hline Lag-day 6 & $1.01(0.99,1.02)$ & $1.04(0.99,1.08)$ & $0.99(0.97,1.02)$ & $0.96(0.92,1.01)$ \\
\hline Lag-day 7 & $1.01(0.99,1.04)$ & $1.06(0.99,1.14)$ & $0.98(0.94,1.01)$ & $0.92(0.85,1.00)$ \\
\hline
\end{tabular}

Bold RRs are significant at 0.05 level
$1.00,1.03)$ was statistically significant. The same phenomenon can be observed for the relationship between $\mathrm{O}_{3}$ and all non-accidental cause mortality $(1.0029,95 \%$ CI 1.0014 , $1.0043)$, cardiovascular $(1.0049,95 \%$ CI 1.0013, 1.0085), 
Table 3 Relative risks (RRs) for the association of cumulative exposure to $10 \mu \mathrm{g} / \mathrm{m}^{3}$ increase in $\mathrm{PM}_{10}, \mathrm{PM}_{2.5}, \mathrm{NO}_{2}, \mathrm{O}_{3}$, and $1000 \mu \mathrm{g} / \mathrm{m}^{3} \mathrm{CO}$

\begin{tabular}{|c|c|c|c|c|}
\hline & All causes & Respiratory & Cardiovascular & Cerebrovascular \\
\hline \multicolumn{5}{|c|}{$\mathrm{PM}_{10}\left(10 \mu \mathrm{g} / \mathrm{m}^{3}\right)$} \\
\hline Lag-day $0-1$ & $1.00(0.99,1.0)$ & $1.03(0.99,1.07)$ & $0.99(0.97,1.01)$ & $0.96(0.93,1.00)$ \\
\hline Lag-day 0-2 & $1.00(0.99,1.0)$ & $1.04(1.00,1.09)$ & $0.99(0.97,1.01)$ & $0.97(0.93,1.01)$ \\
\hline Lag-day 0-3 & $1.00(0.99,1.0)$ & $1.05(1.00,1.10)$ & $0.99(0.96,1.01)$ & $0.98(0.94,1.03)$ \\
\hline Lag-day $0-4$ & $1.00(0.98,1.0)$ & $1.06(1.01,1.12)$ & $0.99(0.96,1.01)$ & $0.99(0.94,1.05)$ \\
\hline Lag-day $0-5$ & $1.00(0.98,1.0)$ & $1.07(1.02,1.14)$ & $0.98(0.96,1.01)$ & $1.00(0.94,1.06)$ \\
\hline Lag-day 0-6 & $1.00(0.98,1.0)$ & $1.09(1.03,1.16)$ & $0.98(0.95,1.01)$ & $1.00(0.94,1.06)$ \\
\hline Lag-day $0-7$ & $1.00(0.98,1.0)$ & $1.12(1.05,1.20)$ & $0.98(0.95,1.01)$ & $0.99(0.92,1.06)$ \\
\hline \multicolumn{5}{|c|}{$\mathrm{PM}_{2.5}\left(10 \mu \mathrm{g} / \mathrm{m}^{3}\right)$} \\
\hline Lag-day $0-1$ & $1.01(0.98,1.05)$ & $1.00(0.90,1.12)$ & $1.00(0.95,1.06)$ & $0.94(0.84,1.07)$ \\
\hline Lag-day $0-2$ & $1.02(0.98,1.07)$ & $1.03(0.91,1.17)$ & $1.00(0.94,1.07)$ & $0.96(0.83,1.10)$ \\
\hline Lag-day 0-3 & $1.03(0.99,1.08)$ & $1.07(0.92,1.23)$ & $1.01(0.94,1.08)$ & $0.98(0.84,1.14)$ \\
\hline Lag-day $0-4$ & $1.04(0.99,1.10)$ & $1.11(0.94,1.30)$ & $1.01(0.93,1.10)$ & $0.99(0.84,1.18)$ \\
\hline Lag-day $0-5$ & $1.05(0.99,1.12)$ & $1.14(0.95,1.36)$ & $1.02(0.93,1.11)$ & $0.99(0.82,1.20)$ \\
\hline Lag-day 0-6 & $1.06(0.99,1.13)$ & $1.17(0.96,1.41)$ & $1.03(0.94,1.13)$ & $0.98(0.80,1.20)$ \\
\hline Lag-day $0-7$ & $1.07(1.00,1.15)$ & $1.18(0.95,1.47)$ & $1.04(0.94,1.16)$ & $0.94(0.76,1.18)$ \\
\hline \multicolumn{5}{|c|}{$\mathrm{NO}_{2}\left(10 \mu \mathrm{g} / \mathrm{m}^{3}\right)$} \\
\hline Lag-day $0-1$ & $1.01(0.96,1.05)$ & $1.02(0.88,1.18)$ & $1.03(0.96,1.10)$ & $0.89(0.77,1.04)$ \\
\hline Lag-day 0-2 & $1.01(0.96,1.06)$ & $1.03(0.87,1.21)$ & $1.04(0.96,1.13)$ & $0.91(0.77,1.08)$ \\
\hline Lag-day $0-3$ & $1.01(0.96,1.07)$ & $1.03(0.86,1.23)$ & $1.06(0.97,1.16)$ & $0.95(0.79,1.14)$ \\
\hline Lag-day $0-4$ & $1.02(0.96,1.09)$ & $1.03(0.85,1.25)$ & $1.08(0.98,1.19)$ & $1.00(0.82,1.22)$ \\
\hline Lag-day $0-5$ & $1.04(0.97,1.11)$ & $1.03(0.83,1.27)$ & $1.10(0.99,1.22)$ & $1.04(0.84,1.30)$ \\
\hline Lag-day $0-6$ & $1.05(0.98,1.13)$ & $1.02(0.81,1.28)$ & $1.11(0.99,1.24)$ & $1.06(0.84,1.34)$ \\
\hline Lag-day $0-7$ & $1.08(0.99,1.17)$ & $1.02(0.79,1.31)$ & $1.12(0.99,1.27)$ & $1.06(0.82,1.38)$ \\
\hline \multicolumn{5}{|c|}{$\mathrm{O}_{3}\left(10 \mu \mathrm{g} / \mathrm{m}^{3}\right)$} \\
\hline Lag-day $0-1$ & $1.01(0.97,1.05)$ & $0.98(0.87,1.10)$ & $1.02(0.96,1.08)$ & $0.97(0.86,1.09)$ \\
\hline Lag-day $0-2$ & $1.01(0.97,1.05)$ & $1.02(0.90,1.15)$ & $0.97(0.91,1.03)$ & $0.93(0.82,1.06)$ \\
\hline Lag-day $0-3$ & $1.03(0.98,1.07)$ & $0.97(0.85,1.12)$ & $1.05(0.98,1.12)$ & $1.09(0.95,1.25)$ \\
\hline Lag-day $0-4$ & $1.01(0.97,1.06)$ & $0.92(0.80,1.07)$ & $1.02(0.95,1.10)$ & $1.00(0.86,1.16)$ \\
\hline Lag-day $0-5$ & $1.02(0.97,1.07)$ & $0.97(0.83,1.13)$ & $1.02(0.94,1.10)$ & $0.92(0.78,1.08)$ \\
\hline Lag-day $0-6$ & $1.00(0.95,1.05)$ & $0.99(0.85,1.16)$ & $0.98(0.90,1.06)$ & $0.92(0.78,1.10)$ \\
\hline Lag-day $0-7$ & $1.02(0.97,1.08)$ & $1.03(0.88,1.21)$ & $0.98(0.90,1.07)$ & $0.91(0.76,1.09)$ \\
\hline \multicolumn{5}{|c|}{$\mathrm{CO}\left(1000 \mu \mathrm{g} / \mathrm{m}^{3}\right)$} \\
\hline Lag-day $0-1$ & $0.99(0.95,1.03)$ & $0.97(0.86,1.08)$ & $0.98(0.93,1.04)$ & $1.03(0.90,1.17)$ \\
\hline Lag-day $0-2$ & $0.98(0.94,1.03)$ & $0.95(0.83,1.07)$ & $1.00(0.93,1.06)$ & $1.08(0.93,1.24)$ \\
\hline Lag-day $0-3$ & $0.98(0.94,1.03)$ & $0.93(0.81,1.07)$ & $1.01(0.94,1.09)$ & $1.12(0.96,1.32)$ \\
\hline Lag-day $0-4$ & $0.98(0.93,1.03)$ & $0.93(0.80,1.08)$ & $1.03(0.95,1.12)$ & $1.16(0.97,1.38)$ \\
\hline Lag-day $0-5$ & $0.98(0.93,1.04)$ & $0.94(0.80,1.12)$ & $1.04(0.95,1.13)$ & $1.15(0.96,1.39)$ \\
\hline Lag-day $0-6$ & $0.99(0.94,1.05)$ & $0.98(0.83,1.17)$ & $1.03(0.94,1.13)$ & $1.11(0.91,1.35)$ \\
\hline Lag-day $0-7$ & $1.01(0.94,1.07)$ & $1.04(0.87,1.26)$ & $1.01(0.91,1.11)$ & $1.03(0.83,1.27)$ \\
\hline
\end{tabular}

Bold RRs are significant at 0.05 level and respiratory $(1.0029,95 \%$ CI $0.9989,1.0070)$ mortality (WHO 2013). These values are lower than our results, but none of our estimates is statistically significant. A different pattern can be identified for $\mathrm{PM}_{2.5}$. According to HRAPIE, all-cause mortality is associated with short-term exposure to $\mathrm{PM}_{2.5}$ with an RR of 1.023 (95\% CI 1.0045, 1.0201) (WHO 2013). These values are higher than the RRs estimated in this study for the non-cumulative exposure, while they are lower than the lag-days $0-3(1.03,95 \%$ CI $0.99,1.08)$ to $0-7(1.07$, $95 \%$ CI 1.00, 1.15). These comparisons show that the application of associations taken from the areas with different range of concentrations in health impact assessment studies should be used with caution since they may under- or over-estimate the mortality rates (Hopke et al. 2018). 
Table 4 Results of sub-group analysis for the association of exposure to $\mathrm{PM}_{10}$ and $\mathrm{NO}_{2}$ with respiratory and IHD mortality per $10 \mu \mathrm{g} / \mathrm{m}^{3}$ increase in concentrations

\begin{tabular}{|c|c|c|c|c|c|}
\hline Cause & Age $<16$ & Age 16-65 & Age $>65$ & Male & Female \\
\hline \multicolumn{6}{|c|}{$\mathrm{PM}_{10}$ Respiratory } \\
\hline Lag-day 0 & $1.09(0.97,1.22)$ & $1.00(0.95,1.04)$ & $1.02(0.99,1.05)$ & $0.99(0.96,1.02)$ & $1.06(1.02,1.10)$ \\
\hline Lag-day 1 & $1.05(0.99,1.12)$ & $0.99(0.97,1.02)$ & $1.02(1.00,1.03)$ & $1.00(0.98,1.02)$ & $1.03(1.01,1.05)$ \\
\hline Lag-day 2 & $1.02(0.97,1.08)$ & $0.99(0.97,1.02)$ & $1.01(0.99,1.03)$ & $1.01(0.99,1.03)$ & $1.01(0.99,1.03)$ \\
\hline Lag-day 3 & $1.01(0.95,1.07)$ & $0.99(0.97,1.02)$ & $1.01(0.99,1.03)$ & $1.01(0.99,1.03)$ & $1.00(0.98,1.02)$ \\
\hline Lag-day 4 & $1.00(0.95,1.06)$ & $1.00(0.98,1.02)$ & $1.01(0.99,1.03)$ & $1.02(0.99,1.03)$ & $1.00(0.98,1.02)$ \\
\hline Lag-day 5 & $1.00(0.95,1.05)$ & $1.01(0.99,1.03)$ & $1.01(1.00,1.03)$ & $1.01(0.99,1.03)$ & $1.01(0.99,1.03)$ \\
\hline Lag-day 6 & $1.00(0.95,1.06)$ & $1.02(0.99,1.04)$ & $1.02(1.00,1.03)$ & $1.01(0.99,1.03)$ & $1.03(1.01,1.05)$ \\
\hline Lag-day 7 & $1.01(0.92,1.10)$ & $1.03(0.99,1.07)$ & $1.02(0.99,1.05)$ & $1.00(0.98,1.03)$ & $1.05(1.02,1.08)$ \\
\hline Lag-day $0-1$ & $1.14(0.97,1.35)$ & $0.99(0.93,1.06)$ & $1.04(1.00,1.09)$ & $0.99(0.95,1.04)$ & $1.09(1.04,1.15)$ \\
\hline Lag-day $0-2$ & $1.17(0.97,1.42)$ & $0.98(0.91,1.06)$ & $1.06(1.01,1.11)$ & $1.00(0.95,1.05)$ & $1.10(1.04,1.16)$ \\
\hline Lag-day $0-3$ & $1.18(0.95,1.46)$ & $0.98(0.90,1.07)$ & $1.07(1.02,1.13)$ & $1.02(0.96,1.08)$ & $1.10(1.03,1.17)$ \\
\hline Lag-day $0-4$ & $1.18(0.93,1.50)$ & $0.98(0.89,1.08)$ & $1.08(1.02,1.15)$ & $1.03(0.96,1.10)$ & $1.10(1.02,1.18)$ \\
\hline Lag-day $0-5$ & $1.18(0.91,1.53)$ & $0.99(0.89,1.10)$ & $1.10(1.03,1.17)$ & $1.04(0.97,1.12)$ & $1.11(1.03,1.21)$ \\
\hline Lag-day $0-6$ & $1.18(0.90,1.55)$ & $1.01(0.90,1.13)$ & $1.12(1.04,1.20)$ & $1.05(0.97,1.14)$ & $1.15(1.05,1.25)$ \\
\hline Lag-day $0-7$ & $1.19(0.88,1.61)$ & $1.04(0.92,1.18)$ & $1.14(1.06,1.24)$ & $1.06(0.97,1.15)$ & $1.20(1.09,1.32)$ \\
\hline \multicolumn{6}{|l|}{$\mathrm{NO}_{2}-\mathrm{IHD}$} \\
\hline Lag-day 0 & $1.16(0.59,2.28)$ & $1.06(0.90,1.24)$ & $1.17(1.04,1.29)$ & $1.13(1.01,1.27)$ & $1.11(0.98,1.26)$ \\
\hline Lag-day 1 & $1.16(0.81,1.66)$ & $1.02(0.94,1.11)$ & $1.10(1.04,1.16)$ & $1.07(1.01,1.14)$ & $1.09(1.02,1.17)$ \\
\hline Lag-day 2 & $1.15(0.83,1.58)$ & $1.00(0.92,1.08)$ & $1.06(1.01,1.12)$ & $1.03(0.97,1.09)$ & $1.07(1.00,1.14)$ \\
\hline Lag-day 3 & $1.12(0.78,1.60)$ & $0.98(0.90,1.08)$ & $1.03(0.97,1.10)$ & $1.00(0.94,1.07)$ & $1.05(0.97,1.13)$ \\
\hline Lag-day 4 & $1.08(0.78,1.49)$ & $0.98(0.90,1.06)$ & $1.02(0.97,1.08)$ & $1.00(0.94,1.06)$ & $1.03(0.96,1.09)$ \\
\hline Lag-day 5 & $1.04(0.80,1.36)$ & $0.98(0.92,1.05)$ & $1.01(0.97,1.06)$ & $1.01(0.96,1.06)$ & $1.00(0.95,1.06)$ \\
\hline Lag-day 6 & $0.99(0.70,1.42)$ & $0.99(0.91,1.07)$ & $1.01(0.96,1.07)$ & $1.03(0.97,1.10)$ & $0.98(0.91,1.05)$ \\
\hline Lag-day 7 & $0.95(0.53,1.69)$ & $1.00(0.87,1.14)$ & $1.02(0.93,1.11)$ & $1.06(0.96,1.16)$ & $0.96(0.86,1.06)$ \\
\hline Lag-day 0-1 & $1.34(0.49,3.65)$ & $1.09(0.86,1.37)$ & $1.27(1.09,1.49)$ & $1.22(1.03,1.44)$ & $1.21(1.01,1.46)$ \\
\hline Lag-day $0-2$ & $1.53(0.50,4.75)$ & $1.08(0.83,1.41)$ & $1.35(1.14,1.60)$ & $1.25(1.03,1.51)$ & $1.30(1.05,1.60)$ \\
\hline Lag-day 0-3 & $1.72(0.50,5.88)$ & $1.07(0.80,1.42)$ & $1.40(1.16,1.68)$ & $1.25(1.02,1.54)$ & $1.36(1.08,1.71)$ \\
\hline Lag-day $0-4$ & $1.86(0.49,7.13)$ & $1.04(0.76,1.43)$ & $1.42(1.16,1.75)$ & $1.25(0.99,1.57)$ & $1.39(1.08,1.80)$ \\
\hline Lag-day $0-5$ & $1.93(0.46,8.12)$ & $1.02(0.72,1.45)$ & $1.44(1.15,1.81)$ & $1.27(0.99,1.62)$ & $1.40(1.06,1.84)$ \\
\hline Lag-day 0-6 & $1.92(0.42,8.68)$ & $1.01(0.70,1.46)$ & $1.46(1.15,1.86)$ & $1.30(1.00,1.70)$ & $1.37(1.02,1.83)$ \\
\hline Lag-day 0-7 & $1.82(0.34,9.79)$ & $1.01(0.67,1.51)$ & $1.49(1.14,1.94)$ & $1.38(1.03,1.84)$ & $1.30(0.94,1.80)$ \\
\hline
\end{tabular}

Bold RRs are significant at 0.05 level

$\mathrm{PM}_{10}$ and $\mathrm{NO}_{2}$ showed the strongest relationships with daily mortality. The same results were also observed in another study in Iran by Dehghan et al. (2018). They found that $\mathrm{NO}_{2}(\mathrm{RR}=1.04,95 \% \mathrm{CI} 1.02,1.07)$ and $\mathrm{PM}_{10}(\mathrm{RR}=1.03$, $95 \%$ CI 1.02, 1.04) were associated with respiratory death on lag-day 0 (Dehghan et al. 2018). In a study in Mashhad, $\mathrm{NO}_{2}$ concentrations during 2011 were significantly associated with daily cardiovascular mortality $(1.01,95 \%$ CI 1.006, 1.014). No significant association was found for $\mathrm{PM}_{10}$ (Ghorbani et al., 2017). In another study in Mashhad, $\mathrm{NO}_{2}$ was statistically related to daily COPD death in 2011 with a ratio of the incidence rate of 1.01. $\mathrm{PM}_{10}$ also was not associated with the COPD mortality (Ghorbani et al., 2019). The difference between our results can be mainly due to the different statistical models, and study period and duration (Nabizadeh et al., 2019).

In another study in Iran, the associations of the six criteria air pollutants with mortality were investigated. The RRs for the association with $\mathrm{PM}_{10}$ on respiratory mortality in lag-day 0, lag-day 14, and lag-day 0-14 were 1.03 (95\% CI 1.00 , 1.051), 1.07 (95\% CI 1.01, 1.13), and 1.03 (95\% CI 1.01, 1.05), respectively. Alternatively, the overall estimates for $\mathrm{NO}_{2}$ associations were not significant, and the RRs for the lag-days 0 and 14 were 0.99 (95\% CI $0.98,1.01)$ and 0.97 $(95 \%$ CI $0.93,1.02)$. Some strong associations were found for $\mathrm{NO}_{2}$ in the sub-group analyses (Dastoorpoor et al. 2018a). Some significant associations in different lag-days have been found in another study in Ahvaz, where ozone on lag-day 3 
Table 5 Results of multipollutant model $\left(\mathrm{PM}_{2.5}+\mathrm{NO}_{2}\right)$ for the association of exposure to $\mathrm{PM}_{2.5}$ and $\mathrm{NO}_{2}$ with all-cause and IHD mortality per $10 \mu \mathrm{g} / \mathrm{m}^{3}$ increase in concentrations

\begin{tabular}{|c|c|c|c|c|}
\hline \multirow[b]{2}{*}{ Lag-days } & \multicolumn{2}{|l|}{$\mathrm{NO}_{2}$} & \multicolumn{2}{|l|}{$\mathrm{PM}_{2.5}$} \\
\hline & All causes & IHD & All causes & IHD \\
\hline Lag-day 0 & $1.01(0.98,1.04)$ & $1.13(1.03,1.24)$ & $1.00(0.97,1.03)$ & $1.00(0.92,1.09)$ \\
\hline Lag-day 1 & $1.00(0.99,1.02)$ & $1.08(1.03,1.13)$ & $1.00(0.99,1.02)$ & $0.98(0.94,1.03)$ \\
\hline Lag-day 2 & $1.00(0.99,1.02)$ & $1.04(0.99,1.09)$ & $1.00(0.99,1.02)$ & $0.98(0.94,1.02)$ \\
\hline Lag-day 3 & $1.00(0.99,1.02)$ & $1.02(0.97,1.07)$ & $1.01(0.99,1.02)$ & $0.98(0.93,1.03)$ \\
\hline Lag-day 4 & $1.01(0.99,1.02)$ & $1.01(0.96,1.06)$ & $1.01(0.99,1.02)$ & $0.99(0.95,1.04)$ \\
\hline Lag-day 5 & $1.01(0.99,1.03)$ & $1.00(0.97,1.04)$ & $1.01(0.99,1.02)$ & $1.01(0.97,1.05)$ \\
\hline Lag-day 6 & $1.02(1.00,1.04)$ & $1.01(0.96,1.05)$ & $1.00(0.99,1.02)$ & $1.03(0.99,1.08)$ \\
\hline Lag-day 7 & $1.03(0.99,1.05)$ & $1.01(0.93,1.09)$ & $1.00(0.98,1.03)$ & $1.06(0.98,1.14)$ \\
\hline Lag-day $0-1$ & $1.01(0.97,1.06)$ & $1.22(1.07,1.39)$ & $1.00(0.96,1.04)$ & $0.98(0.87,1.11)$ \\
\hline Lag-day 0-2 & $1.01(0.96,1.07)$ & $1.27(1.10,1.48)$ & $1.00(0.95,1.05)$ & $0.96(0.83,1.11)$ \\
\hline Lag-day $0-3$ & $1.02(0.96,1.08)$ & $1.30(1.11,1.53)$ & $1.01(0.95,1.07)$ & $0.94(0.80,1.11)$ \\
\hline Lag-day $0-4$ & $1.03(0.96,1.09)$ & $1.31(1.09,1.57)$ & $1.01(0.95,1.08)$ & $0.94(0.78,1.12)$ \\
\hline Lag-day $0-5$ & $1.04(0.97,1.11)$ & $1.31(1.08,1.60)$ & $1.02(0.95,1.09)$ & $0.95(0.77,1.16)$ \\
\hline Lag-day $0-6$ & $1.06(0.98,1.14)$ & $1.32(1.08,1.62)$ & $1.02(0.95,1.10)$ & $0.98(0.79,1.21)$ \\
\hline Lag-day 0-7 & $1.08(1.00,1.17)$ & $1.34(1.06,1.68)$ & $1.03(0.94,1.12)$ & $1.04(0.81,1.32)$ \\
\hline
\end{tabular}

Bold RRs are significant at 0.05 level (among men), $\mathrm{PM}_{10}$ on lag-day 3 and 13 (people aged $>60$ and $<18$ years), $\mathrm{CO}$ in lag-day 11 (people aged $<18$ years), and $\mathrm{NO}_{2}$ in lag-day 13 (people aged $>60$ years) were related to cardiovascular mortality (Dastoorpoor et al. 2018a).

Limited evidence is available in Iran for comparison, especially in the case of $\mathrm{NO}_{2}$. However, due to relatively comparable concentrations, Chinese studies can be a good alternative for comparison purposes. In a multi-site time-series study in China, an IQR increase in $\mathrm{PM}_{10}$ concentrations led to $1.70 \%(95 \% \mathrm{CI}$ $0.01,3.32 \%$ ) increase of daily respiratory deaths (Yang et al. 2015). In a meta-analysis of Chinese time-series studies, a $10 \mu \mathrm{g} / \mathrm{m}^{3}$ increase in $\mathrm{NO}_{2}$ was associated with total mortality (excess rate $(\mathrm{ER})=1.30 \%, 95 \%$ CI $1.19,1.41 \%)$, respiratory mortality $(\mathrm{ER}=1.62 \%, 95 \%$ CI $1.32,1.92 \%)$, and cardiovascular mortality ( $E R=1.46 \%, 95 \%$ CI 1.27, 1.64\%) (Shang et al. 2013).

In our study, the associations for $\mathrm{PM}_{2.5}$ on most of the lagdays were not statistically significant although in a number of cases, the lag-day patterns suggested the possibility of an association. These results are in agreement with previous studies in Mashhad. Ghorbani et al. (2017) and Ghorbani et al. (2019) found that short-term exposure to $\mathrm{PM}_{2.5}$ was not associated with daily cardiovascular mortality (Ghorbani et al., 2017) and COPD mortality (Ghorbani et al., 2019). This result is different from a previous study in Iran. Dehghan et al. (2018) reported that $\mathrm{PM}_{2.5}$ was associated with respiratory mortality on lag-day $0(\mathrm{RR}=1.04,95 \% \mathrm{CI} 1.00,1.08)$, lag-day $1(\mathrm{RR}=$ $1.06,95 \%$ CI 1.02, 1.10), and lag-day $2(\mathrm{RR}=1.04,95 \% \mathrm{CI}$ $1.00,1.08$ ) (Dehghan et al. 2018). In a recent study by Shahsavani et al. (2020), no statistically significant associations were identified between $\mathrm{PM}_{2.5}$ and daily mortality in Ahvaz, while the associations increased significantly during non-dust days in Tehran at lag-days 2 and 3 (Shahsavani et al. 2020). In a systematic review of studies in China, short-term exposure to $10 \mu \mathrm{g} / \mathrm{m}^{3}$ increase in $\mathrm{PM}_{2.5}$ was correlated to total mortality $(\mathrm{ER}=0.38 \%, 95 \%$ CI $0.31,0.45 \%)$, respiratory mortality $(\mathrm{ER}=0.51 \%, 95 \%$ CI $0.30,0.73 \%)$, and cardiovascular mortality ( $\mathrm{ER}=0.44 \%, 95 \%$ CI $0.30,0.54 \%$ ) (Shang et al. 2013). Recent studies have shown that $\mathrm{PM}_{2.5}$ concentrations may not be a good index for exposure assessment. Therefore, $\mathrm{PM}_{2.5}$ daily excessive concentration hours $\left(\mathrm{PM}_{2.5} \mathrm{DECH}\right)$ has been introduced as an alternative (Lin et al. 2017). In a study in Tehran (Iran), an interquartile range (IQR) increase in $\mathrm{PM}_{2.5}$ DECH was related to $2.26 \%$ (95\% CI $0.85,3.69 \%$ ) increase in cardiovascular diseases (D. Chen et al. 2019).

Women and people older than 65 years were more susceptible to short-term exposure to air pollution. In previous studies, older people have been proven to be more affected by outdoor air pollution compared with people in other age groups (Simoni et al. 2015; Renjie Chen et al. 2017). In the study of Dehghan et al. (2018), $\mathrm{NO}_{2}, \mathrm{O}_{3}, \mathrm{PM}_{10}$, and $\mathrm{PM}_{2.5}$ had significant relations with respiratory mortality in the older age groups. $\mathrm{PM}_{10}$ and $\mathrm{PM}_{2.5}$ had stronger effect in age $>60$ years than age $<60$ years (Dehghan et al. 2018). However, a study in Tehran indicated that 0-64 years old people suffered more from $\mathrm{PM}_{2.5}$ pollution than people at older ages (D. Chen et al. 2019). In a study conducted in Ahvaz, people aged over 60 years were more affected by $\mathrm{NO}_{2}$ and $\mathrm{CO}$ than those in younger ages (Dastoorpoor et al. 2018b). In the same study, the effects of $\mathrm{PM}_{10}, \mathrm{O}_{3}$, and $\mathrm{SO}_{2}$ were stronger for women than men (Dastoorpoor et al. 2018b). These results are consistent with the present study. In addition, Dehghan et al. reported that the effect of $\mathrm{NO}_{2}$ and $\mathrm{PM}_{2.5}$ were stronger among 
women (Dehghan et al. 2018). Chen et al. (2019) found that men are more susceptible to $\mathrm{PM}_{2.5}$ DECH than women in the case of cardiovascular mortality (D. Chen et al. 2019). Similar to this, in our study, significant associations found between $\mathrm{NO}_{2}$ and IHD mortality in men were stronger than those in women.

This study has some limitations that should be acknowledged. First, the study period was limited to only 3 years (2014-2018). Longer study periods will provide more reliable results. However, health data before 2014 were not reliable due to insufficiencies in the death registering system. Second, the observed concentrations of air pollutants at the monitoring stations may not provide an accurate estimation for exposure of the whole population. However, there was no other choice for exposure assessment. Third, we used 24-h averaged values for $\mathrm{PM}_{10}, \mathrm{PM}_{2.5}, \mathrm{NO}_{2}$, and $\mathrm{CO}$ that may not properly reflect the effects of short-term peaks. Fourth, assuming the same exposure for all inhabitants on each day is certainly not likely to reflect the actual exposure of the whole population.

\section{Conclusions}

In this study, we investigated the association of short-term exposure to five air pollutants including $\mathrm{PM}_{10}, \mathrm{PM}_{2.5}, \mathrm{NO}_{2}, \mathrm{O}_{3}$, and $\mathrm{CO}$ with daily mortality due to natural cause, respiratory, cardiovascular, and cerebrovascular diseases. For IHD mortality, $\mathrm{NO}_{2}$ on lag-days 0 to $0-7$ was significantly associated with daily death. The other pollutants did not show significant relationships. $\mathrm{PM}_{10}$ had significant associations with respiratory mortality in the whole population, people older than 65 years old, and men in several lag-days. In the case of IHD, $\mathrm{NO}_{2}$ affected older people, men, and women in different lag-days. Adjusting for Ramadan did not affect the results significantly. This study is one of the few studies investigating the relationship of air pollution and mortality in Iran. The results indicated that $\mathrm{NO}_{2}$ and $\mathrm{PM}_{10}$ are more critical for health than the other pollutants in Mashhad. Control policies and actions should be enacted to reduce the concentrations of these pollutants.

Funding information This study was funded by Shahid Beheshti University of Medical Sciences, Tehran, Iran (grant number \#22414).

\section{Compliance with ethical standards}

Conflict of interest The authors declare that they have no conflict of interest.

\section{References}

Abazid RM, Khalaf HH, Sakr HI, Altorbak NA, Alenzi HS, Awad ZM et al (2018) Effects of Ramadan fasting on the symptoms of chronic heart failure. Saudi Medical Journal 39(4):395-400
Atkinson RW, Kang S, Anderson HR, Mills IC, Walton HA (2014) Epidemiological time series studies of PM2.5 and daily mortality and hospital admissions: a systematic review and meta-analysis. Thorax 69(7):660-665. https://doi.org/10.1136/thoraxjnl-2013204492

Braga AL, Zanobetti A, Schwartz J (2001) The lag structure between particulate air pollution and respiratory and cardiovascular deaths in 10 US cities. J Occup Environ Med 43(11):927-933. https://doi. org/10.1097/00043764-200111000-00001

Chen D, Mayvaneh F, Baaghideh M, Entezari A, Ho HC, Xiang Q et al (2019) Utilizing daily excessive concentration hours to estimate cardiovascular mortality and years of life lost attributable to fine particulate matter in Tehran. Iran Science of the Total Environment 134909

Chen R, Cai J, Meng X, Kim H, Honda Y, Guo YL, Samoli E, Yang X, Kan H (2014) Ozone and daily mortality rate in 21 cities of East Asia: how does season modify the association? Am J Epidemiol 180(7):729-736. https://doi.org/10.1093/aje/kwu183

Chen R, Yin P, Meng X, Liu C, Wang L, Xu X, Ross JA, Tse LA, Zhao Z, Kan H, Zhou M (2017) Fine particulate air pollution and daily mortality. A nationwide analysis in 272 Chinese cities. American journal of respiratory critical care medicine 196(1):73-81

Croft DP, Zhang W, Lin S, Thurston SW, Hopke PK, van Wijngaarden E et al (2019) Associations between source-specific particulate matter and respiratory infections in New York state adults. Environmental science technology 54(2):975-984

Dastoorpoor M, Goudarzi G, Khanjani N, Idani E, Aghababaeian H, Bahrampour A (2018a) Lag time structure of cardiovascular deaths attributed to ambient air pollutants in Ahvaz, Iran, 2008-2015. International Journal of Occupational Medicine and Environmental Health. https://doi.org/10.13075/ijomeh.1896. 01104

Dastoorpoor M, Khanjani N, Bahrampour A, Goudarzi G, Aghababaeian $\mathrm{H}$, Idani E (2018b) Short-term effects of air pollution on respiratory mortality in Ahvaz, Iran. Medical Journal of the Islamic Republic of Iran 32:30-30. https://doi.org/10.14196/mjiri.32.30

Dehghan A, Khanjani N, Bahrampour A, Goudarzi G, Yunesian M (2018) The relation between air pollution and respiratory deaths in Tehran, Iran- using generalized additive models. BMC Pulmonary Medicine 18(1):49. https://doi.org/10.1186/s12890-018-0613-9

Ghorbani N, Yazdani-Charati J, Etemadinejad S, Ghorbani N (2019) Relationship between air pollution and mortality rate due to chronic obstructive pulmonary diseases in Mashhad, Iran. [article]. Journal of Mazandaran University of Medical Sciences 28(169):161-168

Ghorbani N, Yazdani Charati J, Etemadinejad S (2017) Relationship between air pollution and mortality rate due to cardiovascular diseases in Mashhad, Iran 2011. [article]. Journal of Mazandaran University of Medical Sciences 26(146):47-55

Guo Y, Ma Y, Zhang Y, Huang S, Wu Y, Yu S et al (2017) Time series analysis of ambient air pollution effects on daily mortality. 24(25): 20261-20272

Hadei M, Hopke PK, Rafiee M, Rastkari N, Yarahmadi M, Kermani M et al (2018) Indoor and outdoor concentrations of BTEX and formaldehyde in Tehran, Iran: effects of building characteristics and health risk assessment. Environ Sci Pollut Res 25(27):2742327437. https://doi.org/10.1007/s11356-018-2794-4

Hopke PK, Hashemi Nazari SS, Hadei M, Yarahmadi M, Kermani M, Yarahmadi E et al (2018) Spatial and temporal trends of short-term health impacts of PM2.5 in Iranian Cities; a modelling approach (2013-2016). Aerosol Air Qual Res 18(2):497-504. https://doi.org/ 10.4209/aaqr.2017.09.0325

Hopke PK, Croft DP, Zhang W, Lin S, Masiol M, Squizzato S et al (2019) Changes in the hospitalization and ED visit rates for respiratory diseases associated with source-specific PM2. 5 in New York State from 2005 to 2016. Environ Res 181:108912 
Lin H, Ma W, Qiu H, Wang X, Trevathan E, Yao Z, Dong GH, Vaughn MG, Qian Z, Tian L (2017) Using daily excessive concentration hours to explore the short-term mortality effects of ambient PM2. 5 in Hong Kong. Environ Pollut 229:896-901

Liu C, Chen R, Sera F, Vicedo-Cabrera AM, Guo Y, Tong S, Coelho MSZS, Saldiva PHN, Lavigne E, Matus P, Valdes Ortega N, Osorio Garcia S, Pascal M, Stafoggia M, Scortichini M, Hashizume M, Honda Y, Hurtado-Díaz M, Cruz J, Nunes B, Teixeira JP, Kim H, Tobias A, Íñiguez C, Forsberg B, Åström C, Ragettli MS, Guo YL, Chen BY, Bell ML, Wright CY, Scovronick N, Garland RM, Milojevic A, Kyselý J, Urban A, Orru H, Indermitte E, Jaakkola JJK, Ryti NRI, Katsouyanni K, Analitis A, Zanobetti A, Schwartz J, Chen J, Wu T, Cohen A, Gasparrini A, Kan H (2019) Ambient particulate air pollution and daily mortality in 652 cities. N Engl J Med 381(8):705-715. https://doi.org/10.1056/NEJMoa1817364

Moolgavkar SH, McClellan RO, Dewanji A, Turim J, Luebeck EG, Edwards M (2013) Time-series analyses of air pollution and mortality in the United States: a subsampling approach. Environ Health Perspect 121(1):73-78. https://doi.org/10.1289/ehp.1104507

Mohseni Bandpi A, Eslami A, Shahsavani A, Khodagholi F, Aliaghaei A, Alinejad A (2016) Water-soluble and organic extracts of ambient PM2.5 in Tehran air: assessment of genotoxic effects on human lung epithelial cells (A549) by the Comet assay. Toxin Rev 36(2):116 124. https://doi.org/10.1080/15569543.2016.1259634

Nabizadeh R, Yousefian F, Moghadam VK, Hadei M (2019) Characteristics of cohort studies of long-term exposure to PM2.5: a systematic review. Environmental Science and Pollution Research. https://doi.org/10.1007/s11356-019-06382-6

Rich DQ, Zhang W, Lin S, Squizzato S, Thurston SW, van Wijngaarden E, Croft D, Masiol M, Hopke PK (2019) Triggering of cardiovascular hospital admissions by source specific fine particle concentrations in urban centers of New York State. Environ Int 126:387-394

Shahsavani A, Tobías A, Querol X, Stafoggia M, Abdolshahnejad M, Mayvaneh F, Guo Y, Hadei M, Saeed Hashemi S, Khosravi A, Namvar Z, Yarahmadi M, Emam B (2020) Short-term effects of particulate matter during desert and non-desert dust days on mortality in Iran. Environ Int 134:105299. https://doi.org/10.1016/j.envint. 2019.105299

Shang Y, Sun Z, Cao J, Wang X, Zhong L, Bi X, Li H, Liu W, Zhu T, Huang W (2013) Systematic review of Chinese studies of short-term exposure to air pollution and daily mortality. Environ Int 54:100 111. https://doi.org/10.1016/j.envint.2013.01.010

Simoni M, Baldacci S, Maio S, Cerrai S, Sarno G, Viegi G (2015) Adverse effects of outdoor pollution in the elderly. Journal of Thoracic Disease 7(1):34-45. https://doi.org/10.3978/j.issn.20721439.2014.12.10

WHO (2013) Health risks of air pollution in Europe-HRAPIE project recommendations for concentration-response functions for costbenefit analysis of particulate matter, ozone and nitrogen dioxide. In: World Health Organization Regional Office for Europe. World Health Organization, Geneva, Switzerland

WHO (2014) Seven million premature deaths annually linked to air pollution. World Health Organization, Geneva

Yang Y, Cao Y, Li W, Li R, Wang M, Wu Z et al (2015) Multi-site time series analysis of acute effects of multiple air pollutants on respiratory mortality: a population-based study in Beijing, China. Science of the Total Environment 508:178-187. https://doi.org/10.1016/j. scitotenv.2014.11.070

Yin P, He G, Fan M, Chiu KY, Fan M, Liu C, Xue A, Liu T, Pan Y, Mu Q, Zhou M (2017) Particulate air pollution and mortality in 38 of China's largest cities: time series analysis. BMJ (Clinical research ed) 356:j667-j667. https://doi.org/10.1136/bmj.j667

Zimhony N, Abu-Salameh I, Sagy I, Dizitzer Y, Oxman L, Yitshak-Sade $M$ et al (2018) Increase in ischemic stroke incident hospitalizations among Bedouin Arabs during Ramadan month. J Am Heart Assoc 7(10):e008018

Publisher's note Springer Nature remains neutral with regard to jurisdictional claims in published maps and institutional affiliations. 